\title{
The Impact of Public Transport Lanes on the Operating Speed of Buses
}

\author{
Marija Burinskiené $\dot{a}^{\mathrm{a}}$, Modesta Gusaroviene $\dot{e}^{\mathrm{b}}$, Kristina Gabrulevičiūtè-Skebiené \\ ${ }^{a}$ Vilnius Gediminas Technical University, Faculty of Environmental Engineering, Research Institute of Territory Planning, \\ Sauletekio av. 11, Vilnius 10223, Lithuania \\ ${ }^{b}$ Vilnius Gediminas Technical University, Faculty of Environmental Engineering, Department of Urban Engineering, \\ Sauletekio av. 11, Vilnius 10223, Lithuania
}

\begin{abstract}
One of the most important means of urban public transport, which is an important factor in the functioning of the city, guaranteeing continuity of economic, social, cultural and other systems and development of the city. Public transport is a mode of transport that can create a competition for private cars. Modernization of passenger transport is one of the most important tasks of the transport system to ensure the speed - one of the most important fast and high-quality transport guarantors.

The main tasks of urban public transport systems were adopted in Vilnius in the Strategic Plan for 2010-2020: to integrate shuttle taxis, private shuttle busses into a unified communications public transport system and ensure their work on market conditions; to develop and implement fast urban communication network. Install existing modes of high-speed traffic route networks, using existing and forming new public transport lanes, implementing priority lanes of traffic at intersections; to optimize the urban public transport network development and modernization. To perform proofreading of urban public transport's routes and schedules by passenger traffic studies evaluating newly formed rapid transport network; to install a public transport terminal in the northern part of the city - in Fabijoniškejs district - for urban and suburban passenger service by reducing the existing bus station traction. New public transport system was installed in Vilnius since 2013 July 1 combining fast, basic and additional routes. Public transport lanes were equipped which reached $35 \mathrm{~km}$ by 1 September 2013.
\end{abstract}

Keywords: public transport; bus lane; speed; Vilnius.

\section{Introduction}

One of the most important transport modes is urban public transport, which is an important factor ensuring sustainability of economic, social, cultural and other activities and the development of a city. Public transport in modern cities remains the main transport mode for the residents of the city, reduces urban street loading by preserving the characteristics of passenger transportation and enables to reduce air pollution, which is caused by huge car traffic flows. Public transport is a mode of transport which is in direct competition with private cars. Modernization of passenger transport is one of the most important tasks of the communication system.

Speed is one of the most important factors ensuring fast and high quality communication. Commercial speed, which is estimated taking into account the distance and travel time from the initial to the final stop, could be discussed as well. However, in this case it could serve only as an indicator describing the problems of urban transport system (congestion, lack of dedicated PT lanes) rather than the evaluation of their actual structural capabilities [1].

Low speed is one of the main causes discouraging people to use public transport. Most problems are caused not by technical faults, but by a considerably increased number of private cars. Automobilization has been increasing very rapidly and the transport quantity is getting close to the maximum street capacity. Additional vehicles on the streets reduce travel speed, which sometimes even equals to zero due to occurring traffic jams [5]. However, when streets are widened to increase their capacity, the problem remains unsolved (Fig. 1). No city has ever solved the problem by leaving more space for driving and parking cars.

Corresponding author: Modesta Gusarovienė. E-mail address: modesta.gusaroviene@vgtu.lt

http://dx.doi.org/10.3846/enviro.2014.112

(C) 2014 The Authors. Published by VGTU Press. This is an open-access article distributed under the terms of the Creative Commons Attribution License, which permits unrestricted use, distribution, and reproduction in any medium, provided the original author and source are credited. 


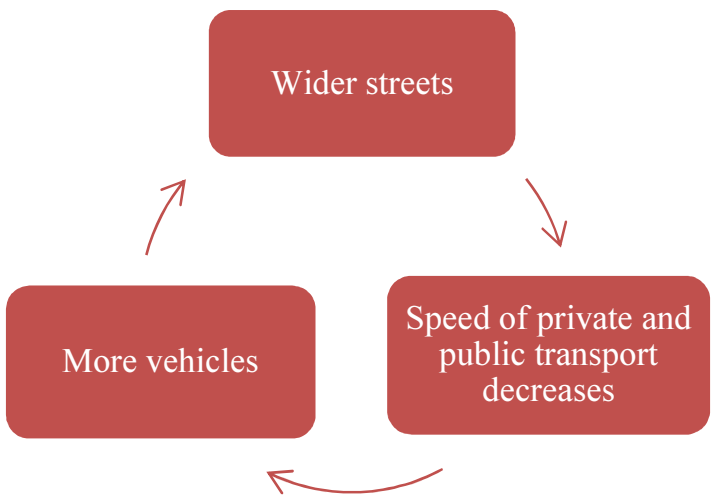

Fig. 1. Ineffective solution

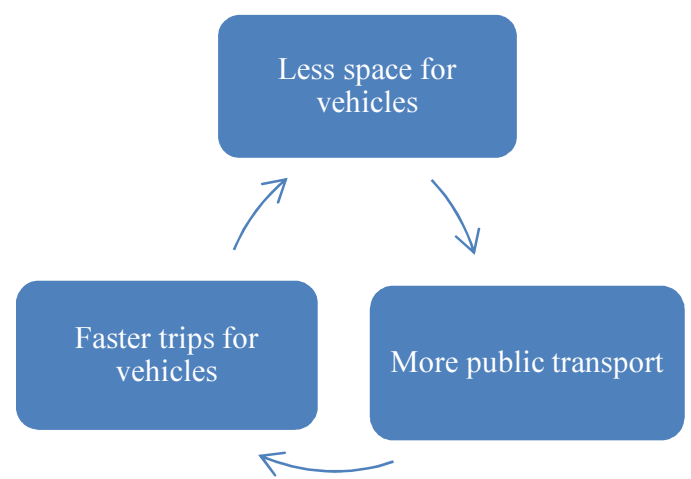

Fig. 2. Effective solution

Vilnius as a capital city of Lithuania plays a special role when performing the functions of national significance. The most important attraction points, such as governmental, scientific, cultural, health care and other important institutions are concentrated in the capital city, where major state significance events, various concerts, festivals, etc. are held. Consequently, due to these reasons the number of inhabitants in the city of Vilnius increases by 1.5 times each year. Thus, to make the general transport system more effective, first of all, it is important to ensure a well-balanced and effective city development, covering the following tasks:

- compact city and the reduction of urban sprawl (scattering);

- increasing the density of the existing residential areas and conversion of industrial areas;

- balancing of residential and work areas, development of mixed build-up;

- regulation of working hours.

\section{Review of sources}

H. B. Zhu (Ningbo University, China) investigates the impact of two different public transport priority models, public transport traffic lanes with interruptions (IBL -intermittent bus lane) and special traffic lanes dedicated only for public transport (DBL - dedicated bus lane), on the change of fundamental functions such as transport flows and their parameters: speed, flow distribution, transport density, etc. Having simulated these models, H. B. Zhu found out that DBL has an obvious advantage of separating public transport from other traffic interference, by giving freedom to movement, speed and regularity. IBL system is effective and applicable as well when improving PT traffic. It is more efficient than ordinary twolane traffic models for all transport modes as the latter inhibit the parameters of public transport capacity, speed and regularity [3].

Based on NaSch model, H. B. Zhu suggests to construct public transport IBL systems because such public transport priority systems do not disrupt general traffic. He has analyzed and simulated the following three two-lane traffic street scenarios: with dedicated bus lane (DBL), an intermittent bus lane (IBL) and an ordinary two-lane traffic street with no priority for PT. Fundamental diagrams were simulated to study the velocity-density profiles in all three cases. It was found out that in the case of DBL, the flow of buses is considerably larger than in other two cases, and the flow of cars is the lowest. It shows that public transport is freed from traffic interference on the dedicated lane; however, it may also disrupt general traffic. It was found out that the strategy of intermittent bus lane is more effective than the strategy of ordinary twolane traffic, meanwhile maintaining the level of general traffic [3].

The three scenarios above were simulated on the assumption that the average bus occupancy is 100 passengers, and the average car occupancy is 3 passengers. Relative ratio $\mathrm{R}$ showing the number of public transport vehicles in the general traffic flow was introduced as well.
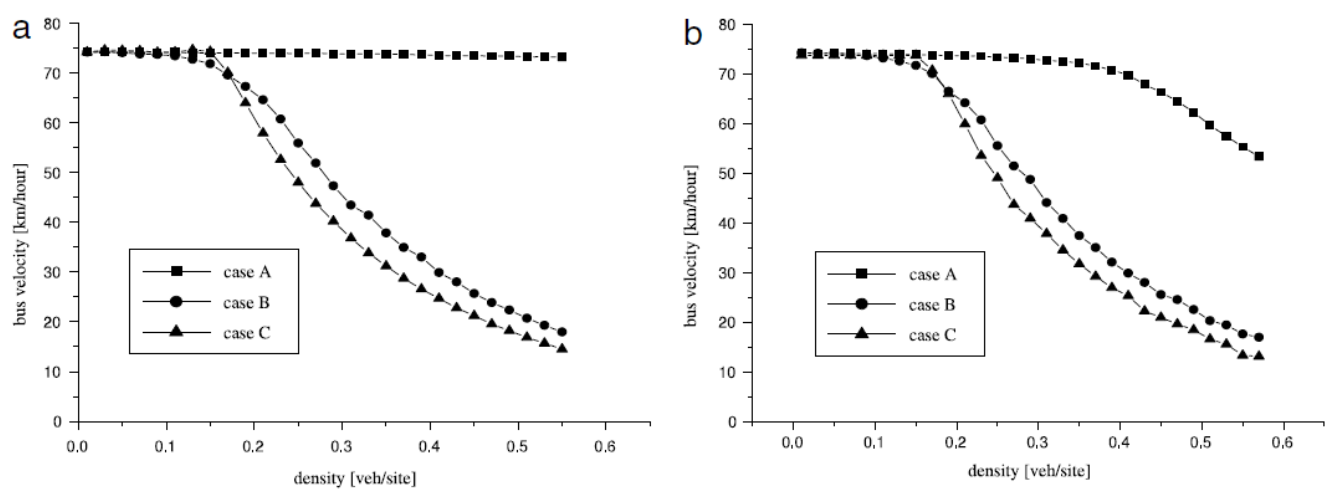

Fig. 3. Bus velocity-density diagrams when (a) $R=0.1$, (b) $R=0.2$ [3] 
Michael Eichler, Carlos F. Daganzo (University of California, USA) also investigate public transport lane models: DBL, when traffic lane is continuously dedicated for public transport and IBL, when a public transport lane operates with interruptions and is available to general traffic. Like Zhu, Eichler and Daganzo, agree about the advantages of dedicated bus lanes. They have admitted that both DBL and IBL are more or less useful when ensuring the speed of passenger transport and its smoother flow. They state that the advantage of intermittent bus lanes over dedicated PT lanes is that IBL do not reduce the capacity of general traffic as much as DBL. However, both models increase the average level of traffic capacity, which is limited, depending on the parameters of streets and intersections [4].

The main factors influencing on the time savings of introducing the intermittent system are as follows: the traffic saturation level; the bus frequency, the improvement in bus travel time achieved by the special lane; and the ratio of bus and car occupant flows [4].

Increasing the competitiveness of public transport is a complex (multi-folded) task. In this context, competitiveness is described as the dependence of public transport supply on other transport modes. The main factors influencing on the competitiveness of PT are travel time, supply of vehicles and price. Regularity, observance of timetable, travel time, proper provision of information about travel make up approximately twenty per cent of values of all public transport quality level [2].

The studies of urban public transport systems in Europe, China, the United States of America, India or South America show that more and more cities in the 21 st century have been focusing on the improvement of the efficiency of the public transport system. It is related not only to the environmental protection, traffic jam problems, which undoubtedly are the main causes impeding on the PT efficiency, but to the improvement of people's social and economic quality of life. Such systems as BRT (Bus Rapid Transit) have been in operation in various cities of the world; the network of dedicated lanes is being developed more and more actively; intelligent transport systems are being implemented to give priority to public transport.

The first traffic lanes dedicated to public transport were opened in all large cities of Europe as well as other continents in the second half of the last century. In Europe, Turin (Italy) and Birmingham (Great Britain), the first PT lanes appeared even before 1960s. In most European countries the decision to introduce dedicated lanes for public transport were not favorably accepted by private car drivers. The residents of Turin (Italy) and Montreal (Canada) were the most positively minded about this idea. The study conducted in Turin showed that even $51 \%$ of private car drivers were ready to use public transport if more bus lanes were opened in the city. Moreover, statistics show that the construction of bus lanes in Birmingham (Great Britain) increased the number of public transport users even by $30 \%$ (Public Transport Authority, 2010). The data leads to the conclusion that the increased number of public transport users may be related to the reduced travel time, which mostly depends on the introduction of dedicated lanes for public transport.

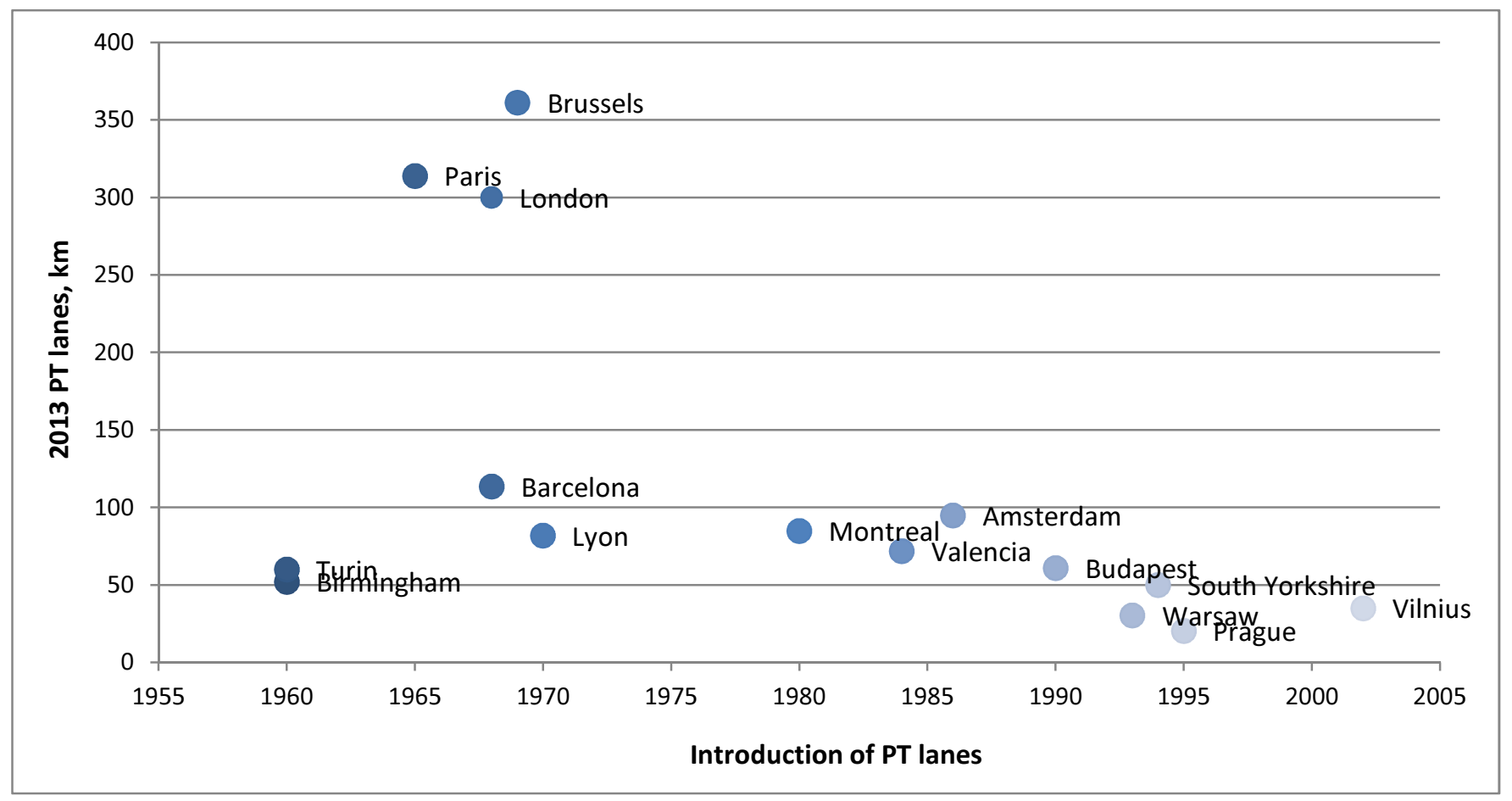

Fig. 4. Introduction of PT lanes in European cities

The population of Helsinki (Finland) is the most similar to that of Vilnius (605,523 inh.). At present, Helsinki has $40 \mathrm{~km}$ of PT lanes, due to which the speed and regularity of buses have improved by $15-20$ per cent [1].

In terms of the population, Amsterdam (the Netherlands) is also very similar to Vilnius. The city has one of the busiest dedicated bus lanes in the world. Every day this dedicated bus lane carries more than tens of thousands of people. Zuidtangent is a bus-rapid-transit network in Amsterdam, which contains two routes. 
Three bus-rapid-transit (BRT) systems operate in Australian cities: Adelaide, Sydney and Brisbane. Public transport specialists from these cities state that the construction of dedicated lanes was one of the most optimal solutions improving the quality of public transport performance. Having analyzed theoretical public transport models and evaluated the knowhow of foreign cities, the following conclusions could be drawn:

- A special (dedicated) PT lane is an effective method to speed up public transport (passengers assess bus lanes positively; facts show that travel time reduces when these lanes are introduced).

- Speed is not a single factor influencing on the number of public transport users. A sufficient number of buses should be offered; convenient routes should be planned and the quality of travel should meet the passengers` expectations.

- When dedicated bus lanes are introduced, the number of public transport users may not change at once as changing the residents" habits and showing the advantages of public transport is a time-consuming process.

- Although private car owners are frequently not satisfied with the introduction of PT lanes, the residents of Montreal and Turin assessed the increased number of bus lanes positively. In Birmingham, when dedicated lanes were introduced, the use of public transport increased even by $30 \%$.

- In Helsinki, it is not only dedicated bus lanes, but transit signal priority (TSP) system that have been successfully implemented, which ensures that the delayed public transport vehicle can change traffic signals to claim the right-of-way and proceed unimpeded through an intersection.

- Amsterdam is a city which has one of the busiest public transport lanes. Lane extension works prove that such lanes are an effective solution when facing traffic jams and aiming to improve and encourage the use of public transport.

\section{Increase of Public Transport Operating Speed in Vilnius City}

The following main tasks set to the city's public transport system were approved in the Strategic Plan of Vilnius city for 2010-2020:

- to integrate taxi and private mini buses into the general PT system and to ensure their work under market conditions;

- to create and implement the city's rapid transit route network. To implement rapid transit route network for the existing transport modes by using the existing and developing new PT traffic lanes and implementing transit signal priority system at intersections;

- to optimize and guarantee the development and modernization of the city‘s public transport route network. To amend the city's PT route and traffic timetables according to the studies of passenger flows, taking into account the newly established rapid transit PT network;

- to construct PT terminal in the northern part of the city in Fabijoniškès for servicing urban and suburban passengers thereby shifting the focus from the existing bus station.

According to the conclusions drawn on the new transport mode implementation in the Special Plan of Vilnius city in 2012, given the equal supply, recently carriage of passengers by city buses has been significantly increasing (1.25 times) and that by trolleybuses has been decreasing (1.4 times). Meanwhile, the general statistical data confirm that passenger flows in the city's public transport have been considerably decreasing [6].

To ensure the effectiveness of the public transport system, first of all, the analysis of the city's public transport network levels was conducted (Fig. 5). The network of routes was prioritized, characterizing each level by certain exploitation parameters, such as speed, traffic interval, service zone [7].

\section{Old PT system}

\section{Main city routes}

- Territory: all territory of the city;

- Transport modes: buses, trolleybuses, mini buses;

- Speed: $12-20 \mathrm{~km} / \mathrm{h}$;

- Traffic interval: 7-60 min.

\section{Local city district routes}

- Territory: territory of separate city districts;

- Transport modes: buses, mini buses;

- Speed: $20-25 \mathrm{~km} / \mathrm{h}$;

- Traffic interval: 30-60 min.

\section{Suburban routes}

- Territory: neighbour suburbs, peripheral part;

- Transport modes: buses, mini buses, trains;

- Speed: $20-25 \mathrm{~km} / \mathrm{h}$;

- Traffic interval: 30-90 min.

\section{New PT system}

Fast routes
- Territory: main zone of the city;
- Speed: > $25 \mathrm{~km} / \mathrm{h}$;
- Traffic interval: $4-6 \mathrm{~min}$;
- Formation principles: reduction of travel time by decreasing the number
of stops, increasing the number of dedicated lanes and introducing
priority traffic conditions.
Main routes
- Territory: main and central city zone;
- Transport modes: buses, trolleybuses;
- Traffic interval: $10-15$ min;
- Formation principles: existing autonomic bus and trolleybus routes.
Access routes
- Territory: peripheral part of the city, suburbs (small capacity buses)
- Transport modes: various capacity buses;
- Traffic interval: according to passenger flow;
- Formation principles: access to fast and main routes, P+R parking lots


The conducted comprehensive studies on passenger flows enabled to review the whole PT network loading, to evaluate redundancy of routes and turnover of public transport stops.

The main aim is to increase the attractiveness of public transport, to reduce operational costs, the need for compensation and to attract as many new passenger transport users as possible at the lowest possible investment thereby reducing the use of private cars on the city streets with all possible consequences: air pollution, congestion, accident rate etc.

Express bus routes were created based on the Special Plan of New Transport Mode Implementation in the city of Vilnius, which provided for the main city passenger flow arteries making up the spine of the public transport network of Vilnius city. Six express bus routes were planned and stops for express buses were selected according to the stops 'turnover.

Vilnius city public transport dedicated lanes. It was in the year 2000 that the first traffic lanes dedicated for public transport were introduced in the city of Vilnius. In 2003, when $8.6 \mathrm{~km}$ of public transport traffic lanes were opened in Vilnius, the average bus and trolleybus speed increased by $2.1 \mathrm{~km} / \mathrm{h}$ and $0.2 \mathrm{~km} / \mathrm{h}$, respectively. In 2004, PT traffic lanes were introduced on the most important trolleybus routes, which impacted on further increase of the average trolleybus driving speed (Fig. 6). In total, $19 \mathrm{~km}$ of PT traffic lanes were introduced in Vilnius city in 2000-2005, which enabled to increase the average driving speed of public transport (for buses by $4.1 \mathrm{~km} / \mathrm{h}$, and for trolleybuses by $0.4 \mathrm{~km} / \mathrm{h}$ ). However, since September 2006 traffic congestion has considerably increased in the city; therefore, PT speed has considerably decreased. Such decrease was impacted by the Governmental Decision on the Amendment of Working Time Regulation, which came into force in 2006, when most passengers go to work at 8 a.m. [7].

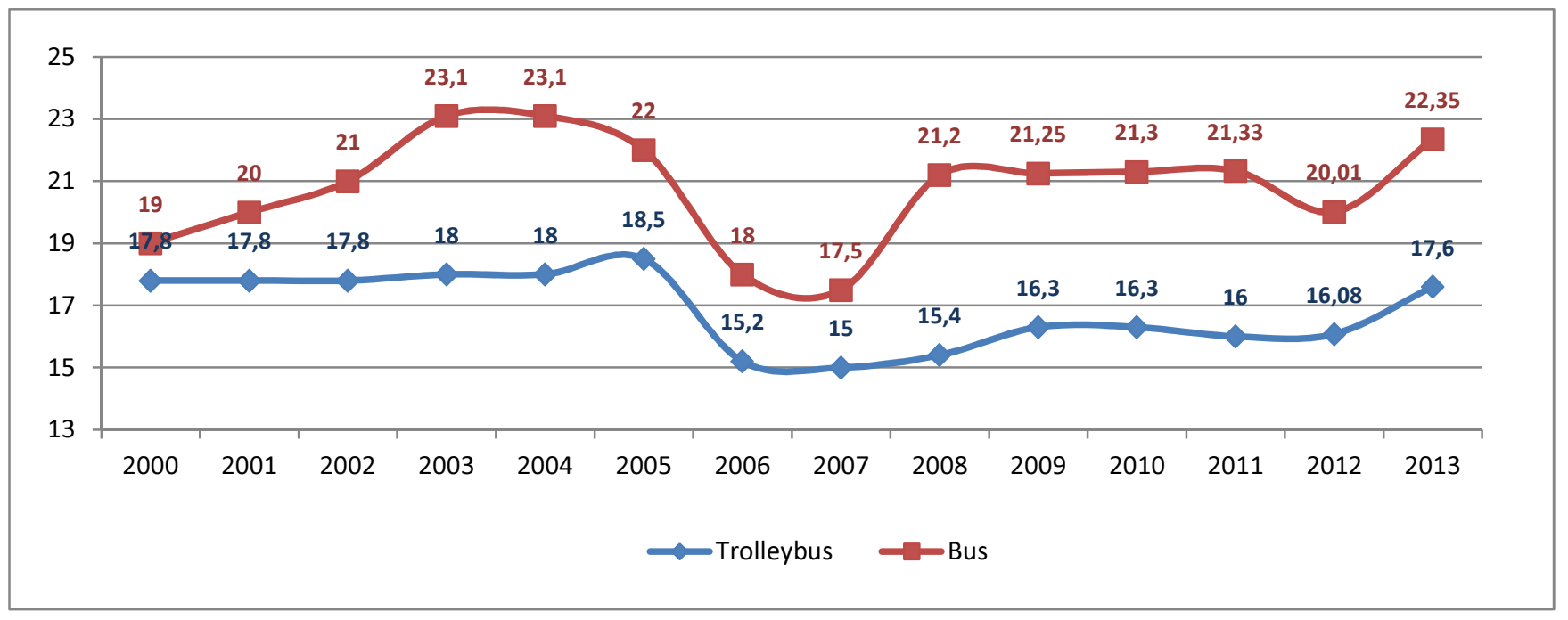

Fig. 6. Dynamics of PT operating speed $(\mathrm{km} / \mathrm{h})$ in 2000-2013 [7]

Although the implemented traffic organization measures were effective until 2005, since 2006 a considerable fall in the speed of PT vehicles has been observed, which was impacted by the changed traffic condition in the city due to the amended working hours, when passenger car flows approximated to overloading limit and considerably reduced the operating speed of PT on Vilnius streets.

Partly, the city of Vilnius started to solve traffic problems in the summer of 2013, when the focus was laid on public transport. The main aim was to create a system, which would ensure faster, more convenient and dependable travel for city residents. As a consequence, when providing carriage services, public transport system and its operators should concentrate on such key criteria as speed and traffic interval, regularity, intermodality and dependability.

On 1 September 2013, approximately 35 kilometers of dedicated PT lanes were available in the city of Vilnius. The location of public transport traffic lanes was selected taking into account the following criteria:

- PT passenger flows at cross-sections of certain streets;

- Private transport passenger flows at cross-sections of certain streets;

- Transport flows on the streets according to the data from traffic light management system;

- Streets' technical parameters: width, number of lanes, width of carriageway;

- Investments into the construction of new lanes;

- Infrastructural parameters. 


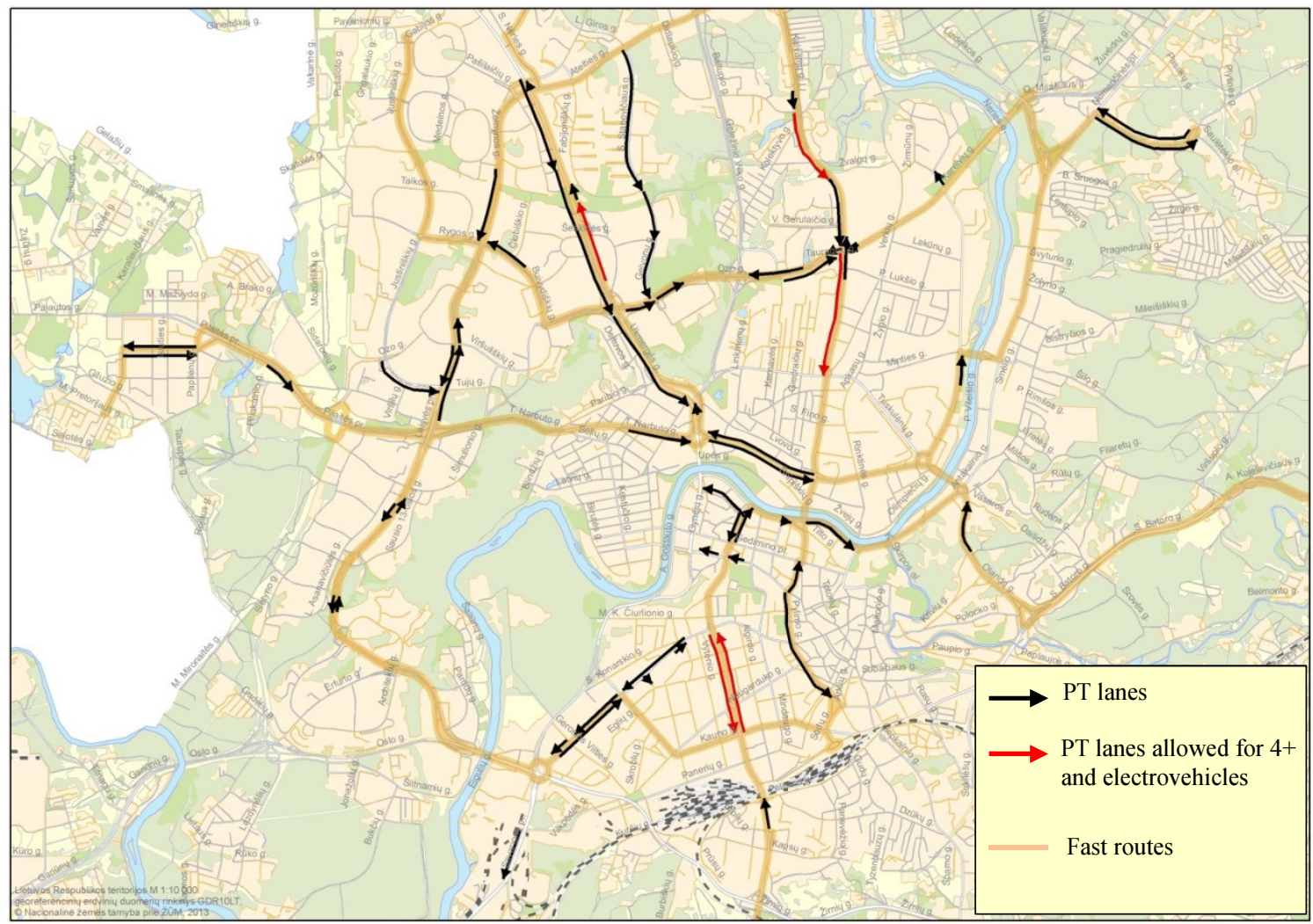

Fig. 7. Network of dedicated traffic lanes in the city of Vilnius in September 2013 [7]

\section{Conclusions}

1. The network of PT lanes may be developed in several stages and integrated into a common system of streets on the basis of the existing street network;

2. PT lanes provide a possibility to improve communication by passenger transport as soon as these lanes are constructed (immediate result);

3. When bus-rapid-transit routes were introduced in Vilnius, which service the main territory of the city covering 75 per cent of residential and work areas, the speed of public transport increased by $6 \mathrm{~km} / \mathrm{h}$ on average. The main measures which increased the speed were the construction of dedicated lanes and marking as well as the reduction in the number of bus stops on bus-rapid-transit routes.

\section{References}

[1] Airaksinen, S.; Kuukka-Ruotsalainen, V. 2012. Bus priority as a competitive factor. Thesis pending, WSP Finland Ltd.

[2] Vanhanen, K. 2007. Factors impacting on the perceived total quality of public transport, with focus on local transport, in Draft 20 Decmber 2006 . WSP Finland $\mathrm{Oy}$, Helsinki, 53

[3] Zhu, H. B. 2010. Numerical study of urban traffic flow with dedicated bus lane and intermittent bus lane. Faculty of Architectural, Civil Engineering and Environment, Ningbo University, Ningbo 315211, China Physica A 389, 3134-3139. http://dx.doi.org/10.1016/j.physa.2010.03.040

[4] Eichler, M.; Daganzo, C. F. 2006. Bus lanes with intermittent priority: Strategy formulae and an evaluation. Department of Civil and Environmental Engineering, Institute of Transportation Studies, University of California, 109 McLaughlin Hall \#1720, Berkeley, CA 94720, United States Transportation Research Part B 40, 731-744. http://dx.doi.org/10.1016/j.trb.2005.10.001

[5] Berger, W. J 2002. The Austrian HOV-lane - experiences in implementation and operation, Journal of civil engineering and management 8(4): 255262. ISSN 1392-3730.

[6] Special plan for new modes of transport deployment in Vilnius city. Conception. Vilnius Gediminas Technical University, $2012 \mathrm{~m}$

[7] Vilnius city Municipal Enterprise ,Susisiekimo paslaugos“ Public transport department Report 2013. 